\title{
Nueva sensibilidad y novela
}

(New Sensibility and Novel)

\author{
Número 2 \\ Junio 2017 \\ p. 206-221 \\ Este número se publicó el 30 de junio de 2017 \\ ISSN: $2448-5942$

\section{Francisco González Gaxiola} \\ Conferencia presentada en el sexagésimo aniversario de la \\ Corresponsalía en Hermosillo del Seminario de Cultura Mexicana. \\ Evento organizado por El Seminario de Cultura Mexicana y \\ la Fundación Cultural José S. Healy. \\ Hermosillo, Sonora. México. 17 de marzo 2016.
}

Derechos de autor: El autor o autores conservan en todo momento sus derechos morales y patrimoniales sobre la obra; la obra no se puede alterar, transformar o ampliar; siempre debe reconocerse la autoría del documento referido. Ninguna de las modalidades de los documentos publicados en Estudios $\lambda a m b d a$. Teoría y práctica de la didáctica en lengua y literatura tienen fines comerciales de naturaleza alguna. 


\title{
Nueva sensibilidad y novela ${ }^{1,2}$
}

\author{
New sensibility and novel
}

FRANCISCO GONZÁLEZ GAXIOLA ${ }^{3}$

\section{RESUMEN}

En esta conferencia expongo las consecuencias que los nuevos tiempos concretados en las nuevas tecnologías han traído sobre las artes, sobre todo en la novela como género emblemático de la narrativa. El punto de partida es que los diversos avatares que ha experimentado la novela la han llevado poco a poco, a veces rápido, a transformarse, y es un hecho que así ha sucedido. El problema aquí singularizado es el preguntar qué tanta transformación puede resistir este género antes de que se convierta en otro género aún no nominado. Por otro lado, existe evidencia de que la nueva dimensión y atmósfera de la cultura posmodernista han desfasado a la novela como centro de las artes. Ahora ese centro es ocupado por una combinación de artes visuales y su parafernalia tecnológica, las artes en las que predomina actualmente la forma y donde ha disminuido su presencia el contenido. Todo ello sin mencionar un sinnúmero de géneros emergentes, innovadores, alentados unos y propiciados otros por los apoyos mediáticos. Falta preguntar por las implicaciones en la Didáctica de la lengua y la literatura.

PALABRAS CLAVE: teoría literaria, polisistemas, nueva sensibilidad, didáctica de la literatura

\begin{abstract}
:
In this lecture I set out the possible consequences that new times, portrayed in new technologies have brought over the arts, mainly on the novel as the emblematic gender in narrative. The point of departure consists of the different avatars that the novel has experimented slowly but surely, sometimes abruptly. Take it for a fact. The particular problem here questions about the amount of transformation to resist before it turns itself into another gender not yet nominated. On the other side, there is evidence that a new dimension and atmosphere of postmodern culture has phased out the novel as central position of the arts. This center is now occupied by a combination of visual arts and its technological paraphernalia, arts in which predominates form over contents and whence the presence of the latter has been diminished. All of this occurs, without still mentioning a great amount of emergent, innovative genders, propitiated some and excited others by the new media supports. We still have to ask about the respective implications on the didactics of literature.
\end{abstract}

KEYWORDS: theory literature, polysystems, new sensibility, didactics of liteature

\footnotetext{
${ }^{1} \mathrm{Al}$ iniciar la conferencia se proyectan sobre una pantalla varias imágenes de arte moderno, pinturas abstractas, esculturas y construcciones de edificios posmodernistas, a la vez se escucha de Pierre Boulez, estructura II.

2 Esta conferencia se inscribe en el marco del proyecto de investigación "Lengua, literatura y muevas tecnologías de la información y la comunicación. Investigación y sus didácticas de su lectura y escritura”. USO318000736

3 Profesor investigador del Departamento de Letras y Lingüística de la Universidad de Sonora. francisco.gonzalez@,unison.mx. Maestría y Doctorado en Lengua y Literatura Españolas por el Departamento de Lenguas Clásicas y Romances, Michigan State University. Posdoctorado en Didáctica de la Lengua y la Literatura en la Universidad de Barcelona (2003). Profesor de Didáctica de la lengua y la literatura, y Teoría literaria en la Universidad de Sonora. Proyectos de investigación: "Las teorías literarias y su aplicación en la enseñanza de la literatura". "La influencia de las nuevas tecnologías en la Didáctica de lengua y literatura".
}

Número 2, Año 2017, ISSN: 2448-5942 
UT PINCTURA POESIS, $y$ asi como sucede en las artes plásticas y auditivas sucede en la novela.

\section{EL CONTEXTO}

Necesitamos un contexto que ubique las artes y su relación con la novela. Nos preguntamos en este contexto, cuál puede ser el sentido y función de las artes y la literatura, y más ahora en nuestro tiempo. El objetivo de las artes ha sido siempre producir placer, entretenimiento, satisfacción, y sentido o sea que nos expliquen el mundo y la sociedad y a nosotros mismos. A partir de las vanguardias las artes no están consiguiendo dichos objetivos al menos no por la vía sensorial, no por la vista, no por la audición. Tampoco desde la teoría de la recepción, lo está consiguiendo la novela. En literatura, necesitamos para explicar el gusto o placer que algunas personas sí obtienen, conviene recordar la dicotomía placer/goce. El primero, de carácter democrático, es para la gran mayoría. Se trata de un placer en el que no hay exigencia de tipo alguno, es un dejarse llevar como la lectura superficial que se realiza al leer una novela erótica o reclinarse en el sillón para ver la televisión. El segundo tipo de placer es más exquisito, exigente, intelectual incluso y no es para cualquiera, pues requiere de una formación lectora, académica, incluso universitaria. Y desde un punto de vista psicológico se inscribe en la teoría constructivista, a la manera, dijéramos de ordenar un rompecabezas de muchas piezas y difícil.

\section{LA NOVELA, QUÉ QUIERE DECIR NOVELA}

Hay muchos tipos de novela. Acaso cuando decimos los académicos novela ¿es para referimos a todo tipo de novela o a uno en particular? ¿La novela burguesa? ¿La novela de vanguardia? ¿La novela de la computadora? Para explicar esto se necesita todo un contexto histórico y poético que nos explique las estructuras de este género literario, su ubicación, tipología, función o funciones.

A la novela la definen varias características, entre ellas: el ser narrativa extensa en prosa, y estar dominada por la mono-línea recta de la lectura, básicamente. El resto de sus características nodales, de origen aristotélico, en las que ha predominado la historia sobre el relato o el

Número 2, Año 2017, ISSN: 2448-5942 
contenido sobre la forma, son las siguientes: desarrollar un argumento unitario en el que ciertos personajes realizan acciones en el tiempo, basadas en la relación causa efecto, con una estructura construida por el triángulo dramático: principio, desarrollo, y clímax con resolución y con un fin: placer, entretenimiento, satisfacción, y sentido. Esta estructura tradicional fue primeramente cuestionada por Lawrence Sterne y el enciclopedista Jacques Diderot, ambos del siglo XVIII, y después negada casi radical y sistemáticamente a partir de las vanguardias, el nouveau roman de mediados del siglo XX en Francia, y la novela de la Europa central, a como le llama Kundera.

La novela ha sido desde hace el imperio romano (novela griega, novela romana, bizantina), un género dinámico, revolucionario, siempre en crisis, tensante, y actualmente, el único género en desarrollo, según los teóricos (M. Bajtín, 1989; G. Lukacs, 1989, W. C. Booth, 1985; N. Frye, 1991. M. Kundera, 1987, ente otros.)

\section{DESCENTRAMIENTO}

El supuesto descentramiento presenta varias posibilidades de explicación: el desgaste de la historia, la forma que se distorsiona, la búsqueda de placer y entretenimiento que la recepción busca en otros medios, y la influencia de los soportes mediáticos.

Primero. La novela se enmarañó en la exploración experimental estructural. De una manera simplificada, O. Cleger (2012), expone seis estructuras que la narrativa del relato ha presentado desde antigüedad hasta los tiempos modernos. ${ }^{4}$

1. Una línea horizontal recta con nodos en la medida que avanza de izquierda a derecha, muy cercana a la que podría tener la historia como sucesión de hechos temporales y causales, a la manera del principio post hoc, ergo propter hoc.

\footnotetext{
${ }^{4}$ Las tales figuras de Cleger (pp. 60-64), que representan la estructura de diversos argumentos narrativos son 1. Una línea horizontal recta con nodos en la medida que avanza de izquierda a derecha; 2. Varias líneas semi-paralelas con nodos en cada una de ellas y en las que varios nodos son compartidos por otras líneas cuando se entrecruzan; 3. Una línea horizontal central con dirección de izquierda a derecha con nodos a lo largo del vector y de los que emergen hacia arriba y hacia abajo ramas laterales; 4. Argumento con forma de red, y en ella muchos nodos, no implica ni principio ni fin, ni orden ni dirección. 5. Argumento en forma de anémona, al menos con un centro del que salen varias ramas que llegan a nodos que se multiplican a su vez en varias ramas; 5. Y por fin el argumento de estructura arborescente que recuerda los diagramas gramaticales de las construcciones de frases y oraciones en la representación arbórea del estructuralismo lingüístico.
}

Número 2, Año 2017, ISSN: 2448-5942 


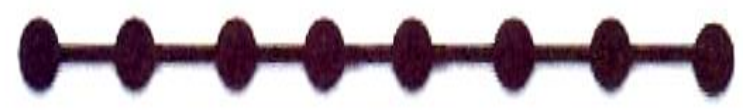

Fig. 1. Argumento como un diagrama de estados transitorios. Fuente: Cleger (2012, 60)

2. Varias líneas semi-paralelas con nodos en cada una de ellas y en las que varios nodos son compartidos por otras líneas cuando se entrecruzan.

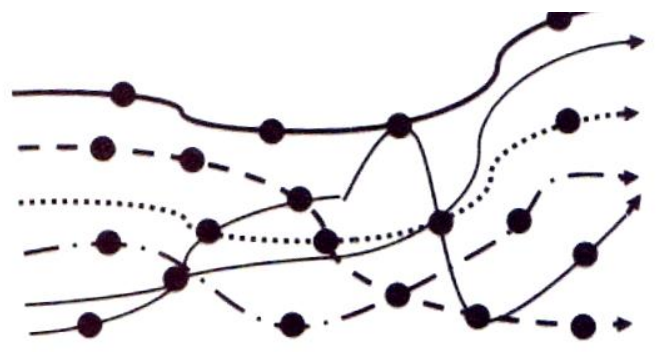

Fig. 2. Argumento de la forma de "destinos entrelazados" o "vidas paralelas". Fuente: Cleger $(2012,61)$

3. Una línea horizontal central con dirección de izquierda a derecha con nodos a lo largo del vector y de los que emergen hacia arriba y hacia abajo ramas laterales

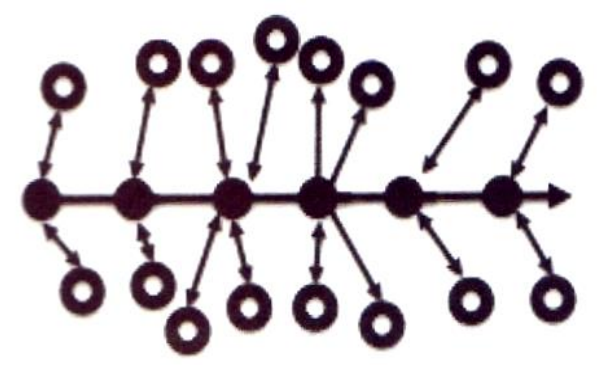

Fig. 3. Argumento en la forma de un vector con ramas laterales. Fuente: Cleger $(2012,63)$

4. Argumento con forma de red, y en ella muchos nodos, no implica ni principio ni fin, ni orden ni dirección.

Número 2, Año 2017, ISSN: 2448-5942 


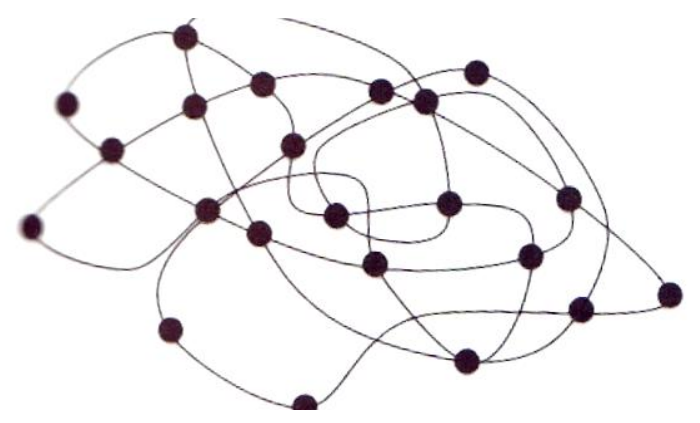

Fig. 4. Argumento con la forma de una red. Fuente: Cleger $(2012,63)$

5. Argumento en forma de anémona, al menos con un centro del que salen varias ramas que llegan a nodos que se multiplican a su vez en varias ramas;

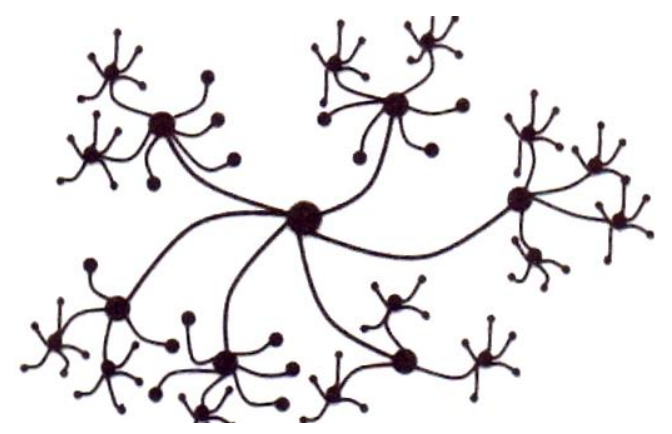

Fig. 5. Argumento con forma de anémona. Fuente: Cleger $(2012,64)$

6. Y por fin el argumento de estructura arborescente que recuerda los diagramas gramaticales de las construcciones de frases y oraciones en la representación arbórea del estructuralismo lingüística.

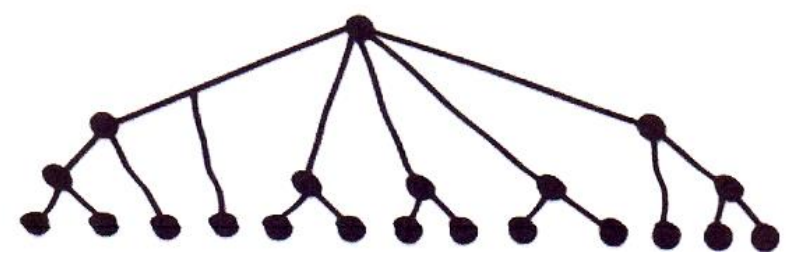

Fig. 6. Argumento de estructura arborescente. Fuente: Cleger $(2012,64)$

En esta sucesión de estructuras de argumentos no se ha considerado el triángulo de G. Freitag, el cual, aunque se aplicó al teatro mucho tiempo y aunque en el Siglo de Oro ha servido para explicar el argumento de la novela dramática o de conflicto.

Número 2, Año 2017, ISSN: 2448-5942 


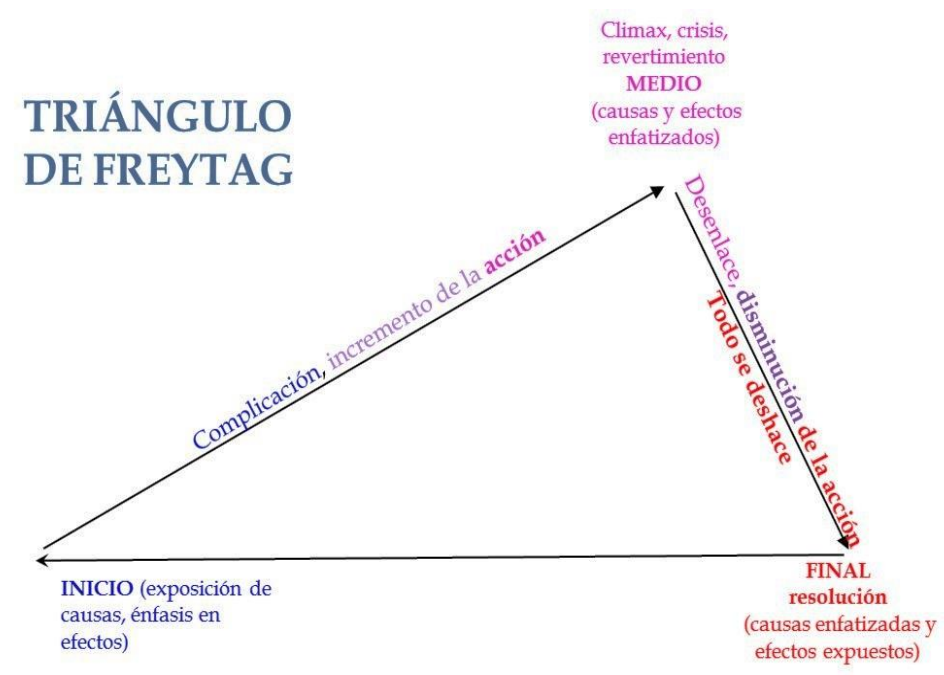

Trama con unidad de acción

Fig. 7. Triángulo de Freytag.

Fue cuestionado tanto por Lope de Vega en España y por Shakespeare en Inglaterra, se le utilizó también como marco explicativo en la narrativa.

El callejón sin salida para la narrativa no lo es tanto; en realidad es la infinidad de caminos que ofrece la novela en su forma más avanzada, la novela de computadora. "El jardín de senderos que se bifurcan"( y también quizá "El libro de arena", como metáfora para un libro infinito) título de un cuento de Borges, es una útil metáfora para de alguna manera representar la infinidad de caminos, que cercanamente se proyectan en la estructura denominada de forma de anémona, de O. Cleger (ver arriba argumento 5 de Cleger). La preocupación por la multiplicación de posibilidades exponenciales, planos, niveles, y caminos en realidad son una manera de orientarse por el número y por la forma y no tanto por la historia. Entre ellas tenemos la cábala en la lectura de la Torá; el I Ching, el método chino de adivinación, el Ars Magna de Raymundo Lullio, la propuesta de Quirinus Kuhlman para producir millones de poemas a partir de uno sólo y que se emparenta con los recientes experimentos del Taller de literatura potencial, OULIPO, de Raymond Queneau, y ahora todas esas posibilidades las tenemos presentes tanto en los videojuegos como en la novela de computadora, (Coover, 1998). ${ }^{5}$

\footnotetext{
${ }^{5}$ Moreno (33-35) refiere varios casos interesantes que asocian el número a la forma: la cábala judía y el I Ching chino, sistemas interactivos de adivinación que prescriben ciertas reglas hermenéuticas de predicción. El Ars Magna de Lullio, sistema numérico
}

Número 2, Año 2017, ISSN: 2448-5942 
En la tradición occidental la estructura del relato está orientada primero por la estructura del mito, en el que el héroe sale en busca de algo o alguien (QUEST). En segundo lugar, la estructura dramática basa su orientación en la Poética de Aristóteles, la cual G. Freitag (1900) retoma y reformula como un triángulo con un ángulo recto cuyo vértice se encuentra abajo y a la derecha. La hipotenusa que une los puntos de los vectores corre de izquierda a derecha, y en ésta línea prácticamente se centra la naturaleza del relato, en la línea que asciende tensándose hasta terminar en el momento climático y en el desenlace que produce la tensión al romperse ${ }^{6}$. En esta orientación, se trata de una flecha que apunta al blanco, la cual puede tardar en llegar o no. Si la flecha tiene prisa, economía y sencillez para presentar una historia, le denominamos cuento. Si por el contrario se vuelve compleja, y si es pródiga en tiempo y lenta en la exposición, le denominamos novela.

El problema de cualquier representación de la estructura de la novela es que no es válida para todos los modelos de narración, lo que hemos mencionado vale para muchas historias, es verdad. Pero, por indicar alguna limitación, el tiempo representado en línea recta, puede volverse circular, o puede complejizarse y adquirir profundidad convirtiéndose en rizoma, o en red con nodos, infinitos. Podemos mencionar aquí el hipertexto y las formas narrativas de lectura interactiva que ofrecen argumento en forma de destinos entrelazados, o vidas paralelas, argumento en forma de vector con ramas laterales, argumento con la forma de una red, argumento con forma de anémona, argumento de estructura arborescente. (Véase nota no. 1)

Segundo. El ser humano aparte de placer y entrenamiento con la lectura de obras donde se narra lo que le sucede a la gente en la sociedad donde vive, necesita que se le explique el evidente caos, la confusión, la naturaleza muchas veces irracional del mundo y la sociedad. Si se siguen experimentando en las novelas con seres confundidos torpes y perdidos, no ayuda a encontrar sentido, objetivo, racionalidad, en las ficciones en las que tratamos de encontrar

que trata de reducir todo el conocimiento a unos cuantos principios. Geor-Philipp Gadsörffer (siglo XVII) con especial atención al simbolismo de los números se inspiró en las armonías numéricas de Pitágoras al considerar que el universo físico y espiritual se correspondían con las armonías musicales y cósmicas. Quirinus Kuhlman (1671) en "Besos de amor celeste" afirma que podría producir millares de poemas a partir de uno. Jean Jacques Rousseau, asignando números a las notas, influyó en la música de John Cage y en discípulos de Schoenberg.

${ }^{6}$ El ángulo que se cierra en triángulo o pirámide es meramente una representación geométrica, útil por lo visual, pero igualmente este tipo de relato puede presentarse como un arco (el arco de siete puntos de Nigel Watts), o un círculo en espiral, o en la más sencilla de las representaciones pero la menos convincente, un vector que avanza de izquierda a derecha, con representación causal y temporal.

Número 2, Año 2017, ISSN: 2448-5942 
sentido explicativo. Por eso es que son y serán de difícil aceptación obras novedosas y juzgadas extraordinarias pero sólo para los especialistas.

Tercero. El predominio de la historia y la disciplina que la estudia: la hermenéutica. Estoy de acuerdo en que es difícil separar forma y contenido, lo cual es un supuesto aceptable, pero no imposible cuando menos para efectos analíticos didácticos. Así pues, desde hace cientos de años se ha prestado una atención exorbitante al contenido o a la historia sobre la forma. Este interés proviene desde las narrativas más antiguas. Cuando las narrativas adquirieron una pátina de contradicción y ambigüedad, perdieron la transparencia significativa, debido principalmente al desfase del tiempo en el que se compusieron o escribieron dichos textos y la sociedad que los recibía después. Desde entonces, desde los tiempos alejandrinos en Egipto, aproximadamente siglo II de nuestra era, surgió la hermenéutica para interpretar precisamente el contenido de los libros sagrados de cristianos y judíos. Dado que la narrativa en general y la novela como forma emblemática de este modo literario, poseen contenido o mucho más contenido que las otras artes, la novela se erigió en la reina delas artes, precisamente porque su contenido podía ser interpretado. Este punto tiene mucho peso y trascendencia pero es de doble filo, porque así como la hermenéutica puede orientarnos en el descubrimiento de un significado oculto también la interpretación puede ofrecer otro producto mediado por la visión del intérprete. (S. Sontag, 1990)

Cuarto. Las NTIC, el hipertexto, los simuladores, los videojuegos o ficciones interactivas, las novelas por computadora, constituyen una inmensa variedad de géneros centrados en los multimedia. Estos géneros han desbancado a la novela enviándola desde el núcleo a alguna órbita (Even Zohar, 1990) todavía cercana, pero ya sin ocupar el centro preponderante. Así pues la novela tradicional, la novela impresa, ha sido desbancada por razones de tipo práctico, economía de tiempo, atractivo visual y sonoro y porque también la imposición de la línea recta en la lectura ha sido superada por un modo de leer conocido como multilineal y que semeja en cierto modo la manera asociacionista en que se comporta el cerebro (tesis cuestionada por Aarseth, 2006), saltando de un término a otro, de una idea a otra sin aparente orden ni causalidad, entre otras razones. Estas últimas opciones en especial la lectura hipertextual, las ofrece ahora libremente la computadora. 


\section{IMPLICACIONES}

Para las currícula de los centros de formación docente especializados en literatura hispánica, generalmente currículas desubicadas y que miran hacia atrás, hacia lo canónico y tradicional, constituyen un lastre para la modernización en la enseñanza de la literatura y una grave barrera para la enseñanza de la literatura en cualquier nivel escolar. Eso también hace que corramos el riesgo de que nuestros egresados queden con una formación desfasada, especializada sí pero anquilosada, en nuestra sociedad posmodernista.

Los profesores, los intelectuales humanistas que estudiamos novelas, dramas y poemas pareciera que no estuviéramos informados y en el caso de que sí lo estuviéramos, da la impresión también que nos es indiferente la situación ya que persistimos en dedicar nuestra mayor atención a los textos canónicos y tradicionales, lo cual no es lo erróneo sino la manera de hacerlo, las estrategias de las NTICs, los recursos, y los apoyos mediáticos que se multiplican cada vez para enseñar incluso a los más antiguas formas literarias, pero también para la enseñanza-aprendizaje de casi cualquier contenido. (A. Mendoza Fillola, 2003)

En el caso que nos ocupa, el de la literatura, algunos teóricos, Schaeffer entre ellos, insisten en que no es la literatura la que está en crisis sino los estudios literarios. Sin embargo, hay noticias para casi todos los géneros, pero especialmente para los de la narrativa, sustentados en la computadora, en la imagen, en la audición y la animación, en la lectura multilineal. Entre estos géneros tenemos el hipertexto, seguido de las redes sociales, los mini-relatos, el cine, la televisión, los juegos computacionales, los simuladores, la realidad virtual a través de la remediación (Bolter y Grusin, 1998) entre muchos más.

Las licenciaturas como carreras profesionales universitarias especializadas en filologías deben actualizar sus contenidos, reforzando los contenidos de los programas de las disciplinas que estudian los soportes, los medios, la multimedia, e incluso los textos canónicos.

Como complemente y ampliación a los supuestos en los que baso mi introducción expongo enseguida observaciones y notas que pueden aclarar algunos aspectos.

Antes que nada es fundamental acotar la referencia para el término novela, pues por el hecho de que se transforma constantemente, no se la puede definir con claridad. Para ello se 
requiere una ubicación, contexto, historia, desarrollo, y situación presente como panorama de las variedades de su género épico.

1. Se ha profetizado en varias ocasiones el fin de la novela (Coover, 1992) lo cual no ha ocurrido todavía; aún así, en la actualidad sigue pareciendo difícil que le ocurra a este género proteico. Lo que se ve es que sus transformaciones en grado crecientemente innovador, convencen sólo a un círculo de académicos, no del todo despreciable sin embargo. Es muy probable que muchas de las modalidades novelísticas que poco importan a los académicos y conocidas como literatura para masas, alienante y evasiva, como las novelas de vaqueros, las de detectives, las novelas de romance, las de ciencia ficción, las de amenazas a la especie humana, como las de vampiros, y las de aventuras de todo tipo, continúen escribiéndose por la demanda del público. Entre ellas tenemos también, más consistentemente, las novelas calificadas como best sellers y una gran mayoría de las novelas de los premios Novel, que están dirigidos a la clase media lectora. Tales productos suelen ser conservadores (ejemplo, la novela policiaca) y por supuesto que no se consideran como novelas propiamente dichas como le gustaría al público lector universitario. Se las llama literatura para masas, para-literatura, sub-literatura, literatura de evasión, pulp fiction, entre otros denominadores

2. La narrativa y en particular la novela ha sido desde los tiempos antiguos el modelo emblemático de las artes, esto es por encima de la pintura, la escultura, la arquitectura, la música inclusive. La razón para tal escenario es la presencia en ella del ostensible contenido semiótico, contenido que a su vez no siendo monosémico, obliga desde tiempos lejanos la curiosidad por saber qué de veras, realmente, quiso decir un artista en su construcción artística. Esto, por supuesto, a diferencia de lo que sucede con las otras artes, cuyo contenido no es tan aparente.

3. Gran parte de la narrativa literaria sobre todo en el siglo $\mathrm{XX}$, a partir de las vanguardias, experimentó un alejamiento de lo mimético, un alejamiento del principio realista en el que se afirma que la novela como género renegaba de la tesis según la cual el lenguaje reflejaba la realidad. En virtud de lo anterior la pintura siguió un proceso similar y con ellos siguió la arquitectura. Incluso la música tendió a alejarse del ritmo y la melodía 
tradicionales con la adopción de una escala de doce notas de la que se derivaron modificaciones interesantes, innovadoras, que parecen convertirla en otro género.

4. El hecho de que la novela posea contenido la convierte en objeto de interpretación y con ello relega el elemento concomitante del contenido, a un segundo lugar, quedando así tantas veces la forma artística relegada y totalmente olvidada. Entiendo que la separación de este binomio forma/contenido es artificial, aun así es importante considerar que durante siglos han sido escasos los tratados orientados a un estudio integral forma/contenido de las artes, y han predominado los tratados, estudios, y comentarios dirigidos a responder la pregunta qué significa esto, qué hay detrás de lo aparente, entre líneas, detrás de la líneas (Cassany, 2006). Esto, sin embargo, es en cierta manera explicable en cuanto que a través del contenido el ser humano busca como objetivo primario de su vida el placer y el entretenimiento, segundo la satisfacción y tercero, aquello que le proporciones sentido y significado a su existencia.

5. La hermenéutica se arroga el derecho de postular un significado distinto al aparente, oculto entre los símbolos de los escritos, otro nivel diferente, profundo, que restituya la congruencia, explique los vacíos, aclare las contradicciones. El crítico literario montado en la exégesis y la hermenéutica como métodos de interpretación busca encontrar lo que verdaderamente quiso decir el artista. Pero al realizar esta operación corre el riesgo de regresar al lector otro producto, otra lectura, otro sentido, otro significado.

6. La tesis sobre el destronamiento de la novela no es nueva, varias veces se la ha enunciado. En 1964 la expresó la escritora, crítica y estudiosa de la teoría literaria Susan Sontag cuando aún no nos invadían los nuevos medios de tecnología de la información y la comunicación. Hoy con mayor razón, la narrativa lineal sea el género que sea, pero en especial la novela de vanguardia, está cada vez más reducida a un público conocedor, entusiasta, formada por académicos generalmente que llaman novela (algo así como LA NOVELA) sólo a los producciones narrativas que buscan reflejar el mundo de otra manera, realista pero innovadora, revolucionaria, desquiciadora, etcétera.

7. En la actualidad los géneros tanto literarios como no literarios, en particular el hipertexto, se han multiplicado en gran medida, y muchos de ellos compiten fuertemente contra la 
novela, al menos en su presentación tradicional, por sustituirla y ocupar el área nuclear de las artes.

8. Actualmente La extensión de la novela, la orientación, la complejidad, la identidad mostrada a través de sus características luchan en contra de ella misma por definir su ontología. La recepción que tenía la literatura, el número de ediciones y re-ediciones de obras se redujo considerablemente en los temas con objetivo de entretenimiento, evasión, escapismo. Aunque, por supuesto, continúan produciéndose y leyéndose, el número de ejemplares es mucho muy reducido. Su declive va acompañado por la caída también de los periódicos versión impresa en el mundo entero. Infinidad de géneros han aparecido, géneros que han desbancado a la novela impresa como forma de placer y entretenimiento. Entre los competidores se incluye la narrativa en su versión breve, la muy breve, el mini-cuento, el mini-relato (L. Zavala, 2012) a las que habrá que sumar todas las versiones en correos electrónicos y twitters también, los que han asestado un fuerte golpe a la que fue en un tiempo la reina de la narrativa. ${ }^{7}$

9. Parece concluirse que las artes a partir de las vanguardias, abandonaron el principio del placer sensorial (visual y auditivo), y pusieron por lo tanto más atención a la forma y no tanto en el contenido. Si la pintura como reproducción mimética de la realidad, de retratos, paisajes, bodegones, fue superada por la fotografía, tuvo a partir de las vanguardias que recurrir a otro objetivo: por ejemplo, el surrealismo apuntó a la construcción de una realidad interior, el impresionismo buscó mediante sus productos motivar las emociones y las impresiones, el expresionismo, impregnar con deformaciones las cosas objeto de la vista humana.

10. Todas las artes están dirigiéndose hacia una nueva sensibilidad que se centra en el acercamiento de la apreciación estética, no sensorial sino intelectual. Habría que ver ahora cuáles fueron las razones que orillaron a las otras artes a escudarse en otros temas

\footnotetext{
${ }^{7}$ A finales de los sesenta cuando apareció la súper novela del boom hispanoamericano, Cien años de soledad, (1967) se publicaban ediciones de 3000 ejemplares, nos da idea de la prudencia en la cantidad de la producción. En la actualidad un autor de mucha trascendencia, original y cuestionador del mismo género, es Paul Auster. Las novelas de la trilogía de Nueva York son cortas, dato que resulta interesante. Sin embargo, hay bastantes novelas extensas que han sido un éxito en ventas, Harry Potter, El código da Vinci, novelones de los premios Novel en narrativa, etcétera. Esto permite y exige un estudio de mercado, por edición, por cantidad de ejemplares, por traducción a otra lengua, por conversión a otro medio, por ejemplo a película, etcétera. Aun así las cosas no son como eran.
}

Número 2, Año 2017, ISSN: 2448-5942 
y otros métodos. Por qué el teatro se volvió irracional, sin sentido, absurdo, alejado de la relación causal? Por qué la música empezó a experimentar con otras escalas, y a integrar el silencio en sus composiciones? Por qué la escultura pierde la armonía, la proporción de las partes, y se agencia la monstruosidad, los huecos, entre otros puntos.

11. Posiblemente la novela para conservarse tenga que desandar su avance hacia los caminos trillados del relatar, o quizá como lo está haciendo ahora, deje de prestar tanta atención a la forma, quizá vuelva a probar el objetivo de contar historias y explicar el mundo a los humanos, su comportamiento, deseos, complejos, aspiraciones, ideas y sentimientos.

Termino este ensayo subrayando que las artes han sufrido una fuerte metamorfosis que las aleja del público no conocedor, público acostumbrado al placer sencillo de los sentidos ante la presencia superficial de estímulos ordinarios que le proporcionaba el mimetismo. Ahora las artes, enfatizando los experimentos formales, exigen una nueva sensibilidad cargada de intelectualismo y para las cuales no estamos ni acostumbrados ni preparados. Existe un desfase evidente entre la producción artística y el público que lo consume. Lo mismo que sucede con las artes plásticas sucede con la música y con la literatura. La literatura se ha vuelto más encerrada en la forma y ha disminuido simultáneamente el contenido. Las implicaciones que esto encierra para la esfera escolar residen en una toma de conciencia para la conformación de los cuadros docentes que se dedican a la enseñanza de la literatura y las artes en todos los niveles educativos.

\section{REFERENCIAS BIBLIOGRÁFICAS}

Aarseth, Espen. "Narrative Literature in the Turing Universe" (pp. 839-870) en The Novel, vol.2 Forms and Themes. Franco Moretti (ed.). Princeton: Princeton UP, 2006.

Bajtín, Mijail. "Épica y Novela” en Teoría y estética de la novela. Madrid: Taurus, 1989.

Barthes, Roland. The Pleasure of the Text. Trad. R. Miller. Nueva York: Hill y Wang, 1975.

Bolter, David Jay, y Peter Grusin. Remediation, Understanding New Media. Boston: MIT Press, 2000.

Booth, Wayne C. Las compañias que elegimos. México: Fondo de Cultura Económica, 1989.

Boulez, Pierre. "Against Hedonism in Musique" referido en Susan Sontag. Against Interpretation. Cassany Daniel. Leer entre líneas. Barcelona: Anagrama, 2006

Número 2, Año 2017, ISSN: 2448-5942 
Cleger, Oswald. "Pantallas saturadas/cuerpos opacos: la ficción hipertextual en lengua española", en Leer hipertextos. Del marco bipertextual a la formación del lector literario. Antonio Mendoza (ed.) Barcelona: Octaedro, 2012.

Coover, R. "Hyperfiction: Novels for the Computers". New York Times Book Review, 1, pp. 8-10, 1998.

Coover, R. “The End of Books”. New York Book Review, 21, junio 1992. http://.nytimes.com/98/09/27/specials/coover-end,html

Eagleton, Terry. Una introducción en la teoría literaria. (primera edición en castellano 1988, y quinta reimpresión).

Freytag Gustav. Technique of the Drama: An Exposition of Dramatic Composition and Art. Traducción autorizada del alemán al inglés por Elías J. MacEwan. Chicago: Scott and Foresman Company, 1900.

Kundera, Milán. El arte de la novela. España: Tusquets, 1987.

Lukacs, Georgy. El alma y sus formas. Teoría de la novela. México, Barcelona, Buenos Aires: Editorial Grijalbo, 1985.

Mendoza Fillola, Antonio. "Didáctica de la lengua y la literatura: aspectos epistemológicos” (pp. 4- 26), en Didáctica de la lengua y la literatura de Antonio Mendoza (ed.) Madrid: Prentice Hall, 2003.

Moreno, Isidro. Musas y nuevas tecnologías. Barcelona. Barcelona: Paidós Ibérica, 2002.

Schaeffer, Jean Marie. Pequeña ecología a los estudios literarios. Por qué y cómo estudiar la literatura. México: Fondo de Cultura Económica, 2013.

Sontag, Susan. Against Interpretation and Other Essays. Nueva York: Picador, 1990.

Watts, Nigel. Writing a Novel. Londres: Hodder \& Stoughton Ltd., 2003.

Zavala, Lorenzo. La ficción posmoderna como espacio fronterizo. Teoria y análisis de la narrativa en literatura y en cine hispanoamericanos. Ciudad de México: Centro de Estudios Lingüísticos y Literarios. El Colegio de México, 2007.

Zohar, Even. Teoría de los polisistemas. www.tau.ac.il/ itamarez/.../EZ-teoria-polisistemas.pdf “Polysystem Theory”. Poetics Today 1979 I, 1-2: 287- 310. Esta versión es la traducción 
de "Polysystem Theory", Poetics Today 11: 1 (Primavera 1990): 9-26. Traducción de Ricardo Bermudez Otero.

Número 2, Año 2017, ISSN: 2448-5942 